\title{
PARTICULARIDADES SOBRE A COVID-19: UMA REVISÃO INTEGRATIVA
}

\author{
FEATURES ABOUT COVID-19: AN INTEGRATIVE REVIEW \\ Paulo César Gottardo, Irla Lavor Lucena Camboim, II* Alexandre de Lima Maehler, III \\ Marcos Alexandre da Franca Pereira, IV Elbia Assis Wanderley, ${ }^{\mathrm{V}}$ Andreia Cristina Fumagalli Cainelli ${ }^{\mathrm{V}}$
}

\begin{abstract}
Resumo. A pandemia por COVID-19 desencadeou um impacto imensurável em todas as esferas sociais, ocasionando um panorama global nunca antes vivenciado, principalmente em populações mais vulneráveis, como os idosos. Assim, o presente trabalho foi desenvolvido com o objetivo de realizar uma revisão sobre o Coronavírus principalmente em pacientes idosos. Para isso, realizou-se uma revisão integrativa por meio de uma metabusca na plataforma MEDLINE/PubMed, da qual foram selecionados 40 artigos após um processo de seleção de 8.911 trabalhos encontrados. Foi realizada uma explanação sobre o processo de doença, suas nuances na população de idosos, sua prevenção e os potenciais suportes terapêuticos. Nota-se que o coronavírus tem sua ação inicial relacionada aos receptores ECA-2, ocasionando um potencial inflamatório, com disfunção endotelial e alterações sistêmicas, as quais se associam a outras alterações imunológicas, que tendem a ter um curso variável em pacientes idosos. Estes, em geral, apresentam uma clínica compatível com uma síndrome gripal, embora tenham um maior percentual de casos atípicos, em relação a população em geral, e uma maior tendência a desfechos desfavoráveis, o que apresenta uma estreita relação com as suas doenças crônicas, as quais, em geral, são fatores de riscos independentes para mortalidade em pacientes com COVID-19. Quanto ao tratamento, um suporte ventilatório adequado, com o uso de corticoesteróides na necessidade de oxigênio, segue sendo consensual, enquanto outras terapêuticas mantêm-se contraditórias, necessitando maiores evidências para seu uso em larga escala. Sendo assim, a prevenção, com o distanciamento social, uso de máscaras e, sobretudo, com a realização da vacinação, segue sendo a principal forma de controle da pandemia.
\end{abstract}

PALAVRAS-CHAVE: Coronavírus. Idosos. SARS-CoV2. Saúde Pública.

Abstract. The COVID-19 pandemic led to an immeasurable impact on all social spheres, causing a global panorama never before experienced, especially in vulnerable populations, such as the elderly. Thus, the present study was developed with the objective of carrying out a review on the Coronavirus mainly in these patients. In order to reach this goal, an integrative review was conducted through a metasearch on the MEDLINE/PubMed platform, from which 40 articles were selected after a screening process through 8911 papers. Through them, an explanation was made about the disease process, its nuances in the elderly population, its prevention and potential therapeutic supports. It has been shown that the coronavirus has its initial action related to ACE-2 receptors, causing a potential inflammatory reaction, with endothelial dysfunction and systemic changes, which are associated with other immunological changes, which tend to have a variable course in elderly patients. These, in general, display symptoms compatible with a flu syndrome, although they have a higher percentage of atypical cases, compared to the general population and a greater tendency to unfavorable outcomes, which is closely related to their chronic diseases, which, in general, are independent risk factors for mortality in patients with COVID-19. As for the treatment, adequate ventilatory support, with the use of corticosteroids in the need for oxygen, remains consensual, while other therapies remain contradictory, requiring more evidence for its large-scale use. Therefore, prevention, with social distancing, the use of masks and, above all, vaccination, remains the main form of pandemic control.

KEYWORDS: Coronavirus. Elderly. SARS-CoV2. Public Health.

IMestre em Medicina Intensiva pela AMIB, Hospital Nossa Senhora das Neves - Unidade Terapia Intensiva. CEP: 58040-530, João Pessoa, Paraíba, Brasil. ORCID ID: 0000-0001-6514-1865.

"IMedica Residente de Medicina Intensiva, Escola de Saúde Pública da Paraíba - SESPB. CEP: 58040-440, João Pessoa, Paraíba, Brasil. *Autor correspondente: irla_camboim@hotmail.com. ORCID ID: 0000-0001-8392-9541.

III Médico Residente de Medicina Intensiva (PEMI), Hospital Nossa Senhora das Neves - Unidade Terapia Intensiva. CEP: 58040-530, João Pessoa, Paraíba, Brasil. ORCID ID: 0000-0002-6045-7681

IV Doutor em Otorrinolaringologia, Hospital Nossa Senhora das Neves - Unidade Terapia Intensiva. CEP: 58040-530, João Pessoa, Paraíba, Brasil. ORCID ID: 0000-0003-1542-7122. 


\section{INTRODUÇÃO}

A rápida propagação de casos relacionados a COVID-19 associada ao número elevado de internações hospitalares e de óbitos traz um retrato fidedigno do impacto dessa pandemia. No final de 2019, os primeiros casos foram diagnosticados em Wuhan (capital da província de Hubei na China) e, já no dia 30 de janeiro de 2020, a Organização Mundial de Saúde (OMS) passou a declarar que esse surto atingira o grau de Emergência de Saúde Pública de Importância Internacional (ESPII), o que configura o maior estrato de alerta da organização, classificando-o como um evento com necessidade de resposta internacional imediata. Sendo bem explícito em números, em setembro de 2021, mais de 200 milhões de casos já foram confirmados no mundo, com mais de 4 milhões de óbitos. No Brasil, já foram mais de 21 milhões de casos de COVID-19 diagnosticados e um total de 587.138 óbitos relacionados a infecção. ${ }^{1}$

Esse padrão de disseminação da pandemia é relacionado a inúmeros fatores. Alguns destes, determinados pelas propriedades do vírus, outros pelo hospedeiro e, por fim, aqueles vinculados à estruturação e dinâmica da sociedade. A soma desses fatores culminou em um efeito global, até então, não constatado na vigência de qualquer outro surto infeccioso.,

A maioria dos pacientes evolui com formas leves ou mesmo assintomáticos. Contudo, em relação aos demais indivíduos, os idosos apresentam uma maior prevalência de casos graves com maiores índices de mortalidade, mostrando uma correlação direta com o maior número de comorbidades encontradas nessa população, associada a elevada fragilidade. ${ }^{3}$ Isso tudo é corroborado por dados da literatura que evidenciam elevação da mortalidade conforme o aumento da faixa etária, podendo ser quatro vezes maior em pessoas de 30 a 39 anos e 570 vezes maior em pessoas de 85 anos ou mais, quando relacionado a grupo de idade entre 18 e 35 anos, cuja incidência da doença foi maior. 4

Infelizmente, apesar de inúmeras drogas e estratégias terapêuticas terem sido avaliadas para o manejo dos pacientes com COVID-19, poucas tiveram resultados significativos e se tornaram consensuais. Entre essas, destacaram-se o uso de anticoagulantes em doses adequadas para o risco e condição clínica de cada paciente e o uso de corticoesteróides para aqueles que necessitam de oxigenioterapia. ${ }^{4}$

Faltam ainda evidências para um tratamento assertivo, principalmente sobre os casos leves. A prevenção segue sendo uma estratégia eficaz para a contenção da pandemia, tendo então, nesse contexto, o uso de máscaras, o distanciamento social e, principalmente a vacinação, como recursos fundamentais que necessitam ser adotados e difundidos. ${ }^{4}$

A abordagem da COVID-19 desde o processo de entrada do vírus no organismo por meio dos receptores ECA-2 até o desenvolvimento dos sintomas iniciais e as suas potenciais complicações é a temática dessa revisão integrativa, dando ênfase a particularidades relacionadas aos pacientes idosos. Desse modo, tem-se como objetivos abordar sobre o processo de doença, sua prevenção e os potenciais suportes terapêuticos, além das condições essenciais para o suporte e o seguimento dos pacientes durante o período pandêmico, sobretudo no âmbito da atenção primária. 


\section{MATERIAL E MÉTODOS}

Foi realizada uma revisão integrativa da literatura a partir da pesquisa de artigos científicos em uma base de dados online, tendo sido necessário cumprir fases distintas essenciais para elaboração: reconhecimento da temática e levantamento das questões que norteiam o estudo; estabelecimento de critérios para inclusão e/ou exclusão de estudos para a busca de literatura científica; definição das informações a serem extraídas dos estudos; avaliação dos estudos; interpretação dos resultados e apresentação da revisão/síntese do conhecimento.

Para tanto, a coleta de dados foi realizada em dezembro de 2020, por meio de metabusca na plataforma MEDLINE/PubMed. Foram utilizados os Descritores em Ciências da Saúde (DeCS) "Idoso", "Idoso frágil", "COVID-19", "SARS-CoV2" e "Saúde Pública", assim como seus respectivos termos no Medical Subject Heading (MeSH), "Elderly", "Frail Elder", "SARS-CoV2", "COVID-19" e "Public Health", combinados por meio do conector booleano "AND".

Foram incluídos artigos com eixo central sobre a abordagem da COVID-19,

\section{RESULTADOS E DISCUSSÃO}

Com a realização da metabusca descrita, foram elegidos inicialmente 8.911 artigos na plataforma MEDLINE. Conforme critérios de inclusão e exclusão, 494 artigos foram inicialmente selecionados. Seguindose com a leitura flutuante dos resumos, 125 artigos foram destacados pela sua relevância (avaliação subjetiva) e foram lidos de modo integral. Desse modo, 40 artigos foram selecionados, sendo somado a esses, as desde a sua fisiopatologia até o tratamento e particularidades relacionadas aos pacientes idosos, considerando os artigos no idioma inglês, português e espanhol, publicados no ano de 2020, incluindo sempre àqueles envolvendo indivíduos com idade superior a 18 anos. Optou-se por excluir da busca publicações como: teses, dissertações, monografias, trabalhos de conclusão de curso, relatos de caso, relatos de experiência, manuais, resenhas, notas prévias, artigos que não continham resumos e/ou texto completo disponíveis, ou que não retratavam uma abordagem sistêmica sobre a temática.

A definição das informações a serem extraídas dos estudos foram basicamente aquelas relacionadas a ação do vírus no ser humano, a apresentação clínica, os métodos de suporte terapêutico e de prevenção, com ênfase na abordagem em idosos. A avaliação dos estudos levou em conta o grau de evidência destes, apresentando, assim, melhor rigor metodológico e maior adequação ao contexto social nacional, resultando, por fim, na extração de dados que culminou na presente revisão.

informações da OMS sobre a COVID-19.

Todos os artigos selecionados foram publicados em inglês. Dois estudos são casos clínicos (5,26\% dos trabalhos), 20 estudos observacionais (52,63\%) e 16 trabalhos de revisão (42,10\%). Entre os artigos de revisão, 5 foram revisões sistemáticas. O fluxograma representando a síntese da estratégia de busca e seleção de artigos encontra-se na Figura 1. 




FIGURA 1. Fluxograma de identificação, seleção, inclusão e exclusão de publicações na revisão integrativa.

O conteúdo selecionado na leitura dos artigos escolhidos versaram sobre os principais tópicos envolvidos no processo de doença da COVID-19 no paciente idoso, desde o momento de sua transmissão até a sua forma de acometimento, sintomas e tratamento, além de um enfoque especial na prevenção da contaminação pelo SARS-CoV2 e também no suporte das comorbidades frequentemente associadas a rotina de vida dessa população.

\section{Aspectos Gerais a cerca do Vírus SARS-CoV-2 e a COVID-19}

A infecção de seres humanos e de outros mamíferos por coronavírus não é uma novidade. Geralmente, essas enfermidades tendem a cursar com doenças respiratórias, neurológicas e gastrointestinais. $\mathrm{O}$ novo Coronavírus (2019-nCoV) foi denominado de SARS-CoV-2 (coronavírus de síndrome respiratória aguda grave 2) pelo Coronavirus Study Group do International Committee on Taxonomy of Viruses. ${ }^{5}$ Trata-se de um vírus da ordem Nidovirales, família Coronaviridae (sub-família Orthocoronavirinae), do tipo Beta, o qual causa geralmente infecções em humanos (Figura 2), ${ }^{6}$ possuindo algumas semelhanças com outros beta-coronavírus, como o vírus da síndrome respiratória aguda grave (SARS) e o vírus da Síndrome Respiratória do Oriente Médio (MERS). ${ }^{7,8}$ A OMS $^{2}$ designou como COVID-19 a doença relacionada à infecção por esse vírus no dia 19 de fevereiro de 2020.

O SARS-CoV-2 é um grande vírus de RNA de fita simples positiva, envelopado que 


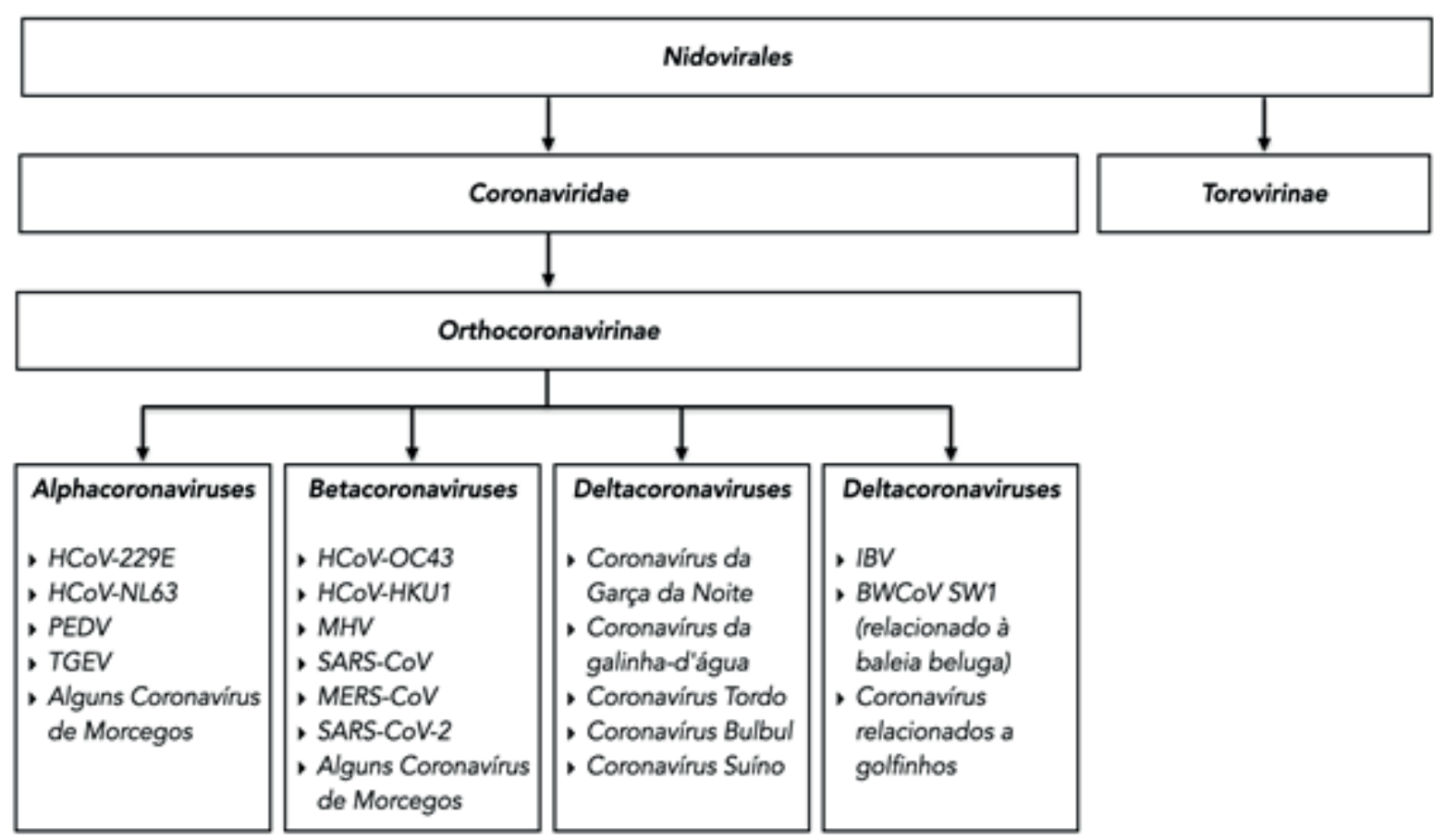

FIGURA 2. Classificação dos Coronavírus em relação a ordem, família, subfamília e gênero, respectivamente. Fonte: Ashour et al. ${ }^{6}$

atua no hospedeiro por meio da ligação de sua proteína de superfície (proteína spike) com o receptor da enzima conversora de angiotensina 2 (ECA2), conforme demonstra
Figura 3, tendo também relevância para a sua entrada no hospedeiro a protease celular TMPRSS2. ${ }^{9}$

\section{SARS-CoV-2 Proteína Spike}
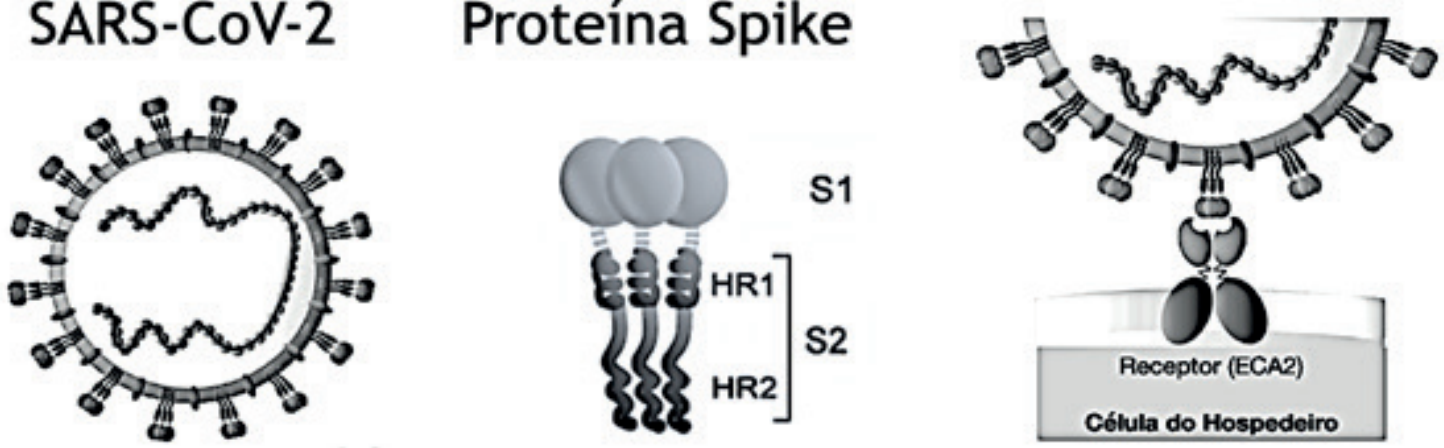

FIGURA 3. Molécula SARS-CoV-2 com detalhamento da Proteína Spike em sua ligação com o receptor ECA-2. Fonte: Huang et al. 9

Os receptores ECA-2 encontram-se difundidos em diferentes órgãos e tecidos. A ligação do SARS-CoV-2 com a ECA-2 inativa esses receptores, interrompendo a transformação da Angiotensina 2 em Angiotensina 1-7, a qual tem potencial antiinflamatório, antifibrótico e vasodilatador.
O efeito resultante desse processo é uma maior ação da Angiotensina 2, com uma ação pró-inflamatória, com vasoconstrição, liberação de radicais livres e fibrose, nos tecidos acometidos, além de perder as ações da Angiotensina 1-7, as quais têm efeito protetor para o organismo (vasodilatação, 
anti-hipertrófico, antiarritmogênico, antifibrótico e com aumento da natriurese). ${ }^{10}$

A partir da ligação com os receptores ECA-2, inúmeros processos fisiopatológicos passam a coexistir, com diferentes magnitudes, consoante as nuâncias de cada indivíduo, da cepa e do inóculo viral. Entre esses processos de doença, a inativação da ECA-2 tem um papel de destaque, o que em geral tende a desempenhar uma atividade pró-inflamatória e fibrótica, interferindo em nível sistêmico na regulação do volume intravascular e do balanço hídrico, além da homeostase local, com alterações da proliferação e crescimento celular e da síntese protéica com manifestações específicas em cada tecido (Tabela 1).

TABELA 1. Sítios de distribuição dos receptores ECA-2 e as consequências subsequentes da sua inativação.

\begin{tabular}{|c|c|c|}
\hline Órgão Acometido & Expressão da ECA-2 & Alteração Decorrente da Inatividade da ECA2 \\
\hline $\begin{array}{l}\text { Pulmão e } \\
\text { Vias Aéreas } \\
\text { Superiores }\end{array}$ & $\begin{array}{l}\text { - Células Epiteliais Ciliads } \\
\text { - Células Caliciformes } \\
\text { - Pneumócitos Tipo II } \\
\text { - Vascularização Pulmonar }\end{array}$ & $\begin{array}{l}\text { - Aumento da Inflamação } \\
\text { - Aumento do remodelamento vascular } \\
\text { - Disfunção endotelial } \\
\text { - Disfunção cardiopulmonar }\end{array}$ \\
\hline Coração & $\begin{array}{l}\text { - Cardiofibroblastos } \\
\text { - Cardiomiócitos } \\
\text { - Células Endoteliais } \\
\text { - Pericito } \\
\text { - Células Adiposas Epicárdicas }\end{array}$ & $\begin{array}{l}\text { - Aumento de Radicais Livres } \\
\text { - Aumento de Hipertrofia } \\
\text { - Aumento da Inflamação } \\
\text {-Aumento da Atividade da MMP (meraloproteinase } \\
\text { matricial) } \\
\text { - Alterações metabólicas } \\
\text { - Alteração do Sistema de Condução } \\
\end{array}$ \\
\hline $\begin{array}{l}\text { Vasos } \\
\text { Sanguíneos }\end{array}$ & $\begin{array}{l}\text { - Células Endoteliais } \\
\text { - Células Angiogênicas } \\
\text { Migratórias } \\
\text { - Células Musculares Lisas } \\
\text { Vasculares }\end{array}$ & $\begin{array}{l}\text { - Aumento de Radicais Livres } \\
\text { - Redução do óxido nítrico endotelial } \\
\text { - Aumento da Disfunção Endotelial } \\
\text { - Aumento da hipertrofia vascular }\end{array}$ \\
\hline Cérebro & $\begin{array}{l}\text { - Órgãos Cicunventriculares } \\
\text { - Tronco Cerebral }\end{array}$ & $\begin{array}{l}\text { - Neuro-inflamação } \\
\text { - Elevação de citocinas } \\
\text { - Ativação da micróglia }\end{array}$ \\
\hline Medula Óssea & - Células Mesangiais & $\begin{array}{l}\text { - Aumento da mieloidose } \\
\text { - Redução das células reparatórias vasculares }\end{array}$ \\
\hline Intestino & - Enterócitos & $\begin{array}{l}\text { - Disbiose intestinal } \\
\text { - Perda da integridade da barreira epitelial (translação } \\
\text { bacteriana) }\end{array}$ \\
\hline Adipócitos & $\begin{array}{l}\text { - Receptores mais concentrados } \\
\text { nos adipócitos perivasculares }\end{array}$ & $\begin{array}{l}\text { - Aumento da captação de glicose } \\
\text { - Aumento da resistência a insulina }\end{array}$ \\
\hline Fígado & $\begin{array}{l}\text { - Hepatócitos } \\
\text { - Colangiócitos } \\
\end{array}$ & $\begin{array}{l}\text { - Aumento da resistência à insulina } \\
\text { - Aumento da fibrose }\end{array}$ \\
\hline Pâncreas & $\begin{array}{l}\text { - Células alfa, beta, delta, epsilon, } \\
\text { acinares. endoteliais, PP e } \\
\text { Mesenquimais }\end{array}$ & $\begin{array}{l}\text { - Redução da secreção de insulina } \\
\text { - Aumento de radicais livres } \\
\text { - Aumento da inflamação }\end{array}$ \\
\hline Rins & $\begin{array}{l}\text { - Células Endoteliais Glomerulares } \\
\text { - Células Endoteliais Tubulares } \\
\text { Proximais } \\
\text { - Podócitos } \\
\end{array}$ & $\begin{array}{l}\text { - Aumento de radicais livres } \\
\text { - Aumento da hipertrofia celular } \\
\text { - Aumento da Inflamação }\end{array}$ \\
\hline $\begin{array}{l}\text { Músculos } \\
\text { Esqueléticos }\end{array}$ & $\begin{array}{l}\text { - Apresentação difusa, com } \\
\text { destaque as paredes das } \\
\text { arteríolas aferentes }\end{array}$ & $\begin{array}{l}\text { - Aumento da resistência à insulina } \\
\text { - Aumento da fibrose }\end{array}$ \\
\hline Olhos & $\begin{array}{l}\text { - Células Epiteliais Pigmentare } \\
\text { - Células Fotorreceptoras (cones } \\
\text { e bastonetes) } \\
\text { - Células Gliais de Muller }\end{array}$ & $\begin{array}{l}\text { - Formação e drenagem do humor aquoso } \\
\text { - Aumento da pressão intra-ocular } \\
\text { - Proliferação celular trabecular }\end{array}$ \\
\hline
\end{tabular}


Estas, associadas a resposta imune e inflamatória do paciente e ao potencial de lesões citopáticas pelo vírus, desencadeiam uma doença sistêmica com diferentes graus de acometimento orgânico e complicações variadas, as quais têm relação com as comorbidades prévias de cada indivíduo. ${ }^{10,11}$

A interação dos fatos já citados ocasiona uma cascata de eventos cuja magnitude de cada fator é muito difícil de ser prevista, levando a diferentes fenótipos de apresentação. As características de cada paciente têm um papel significativo nesse contexto, como também as próprias propriedades do vírus, como sua cepa, e o inóculo viral. Assim, a resposta inflamatória pode ser mínima, sem ocasionar nenhum dano associado, ou exacerbado, com consequências diversas, como a Coagulação Intravascular Disseminada (CIVD), a Síndrome de Ativação de Macrófagos, a Linfohistiocitose Hemofagocítica Secundária e a Síndrome do Desconforto Respiratório Agudo (SDRA), com potencial progressão para Disfunção de Múltiplos Órgãos e Sistemas (DMOS), elevando assim, o risco de óbito.

Nesse processo, alguns pontos são destacados: a inibição da ECA-2 e o amplo processo inflamatório, como também a disfunção endotelial e os eventos de trombose, o que orienta inclusive os pilares atuais de tratamento desses pacientes. ${ }^{4,12}$

Pacientes infectados com COVID-19 apresentam um tempo de incubação de 5 a 7 dias e são normalmente hospitalizados após 3 a 4 dias antes da admissão à Unidade de Terapia Intensiva e/ou ventilação mecânica. Esse padrão subagudo de progressão aumenta a possibilidade de que a imunossupressão, devido à depleção e exaustão de células $T$, contribua para a persistência e mortalidade viral do COVID-19. ${ }^{12}$

Uma resposta imune adaptativa mediada por células T intacta é essencial para manter a supressão a longo prazo de infecções virais. Isso éapoiado pelo aumento significativo do risco de reativação viral em pacientes cujo sistema imunológico adaptativo é suprimido. É assim caracterizada por ativação antigênica persistente de células $T$, conduzindo a um estado de célula não responsiva conhecido como célula $\mathrm{T}$ em exaustão e não por mera ausência de ativação as respostas das células $\mathrm{T}$ (Figura 4).

Dessa forma, frequentemente acompanha-se de linfopenia, anormalidade laboratorial mais consistente em pacientes

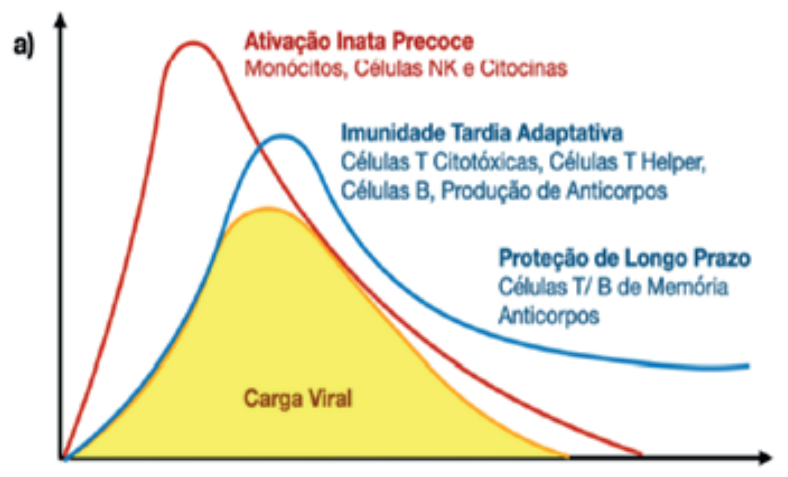

Infecçẫo Viral Controlada / Aguda

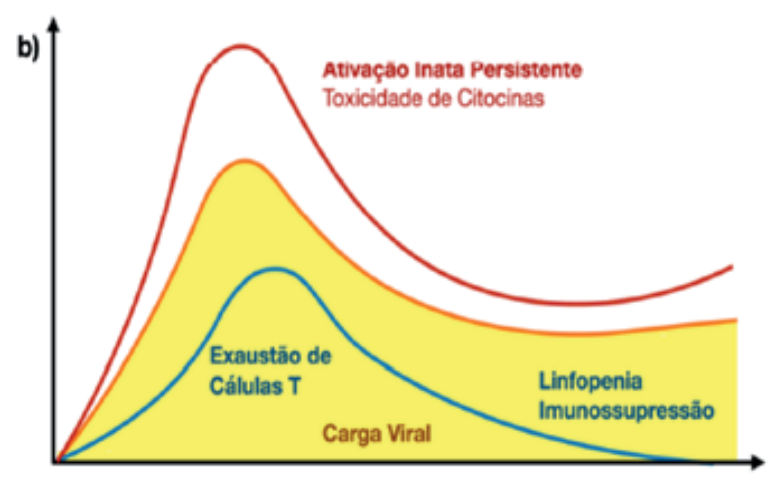

Infecção Viral Crônicas / Não-Controlada

FIGURA 4. Apresentação do curso de doença perante a resposta imune inata e adaptativa, associada à carga viral em pacientes com doença aguda e controlada $(A)$ e naqueles com infecção não controlada, tendendo a cronificação, o que ocorre mais frequentemente em idosos e imunossuprimidos (B). Fonte: Vardhana e Wolchok ${ }^{12}$ 
infectados com COVID-19. Notavelmente, a linfodepleção progressiva é observada em pacientes que se deterioram clinicamente durante a infecção por COVID-19, enquanto a recuperação da contagem de linfócitos tende a preceder diretamente a recuperação clínica. $^{12}$

Seguindo a depuração viral, a maioria das células $T$ específicas do vírus sofre apoptose. No entanto, a manutenção de células $T$ de memória específica para a população viral existente é necessária para imunidade antiviral a longo prazo. A diminuição da função imune adaptativa relacionada à idade, também conhecida como "imunosenescência", é caracterizada por uma perda de diversidade clonal de células T e uma contração de células $T$ ingênuas com capacidade proliferativa. ${ }^{12}$
Esses fatores, acrescidos da influência de potenciais intervenções terapêuticas, como uso indiscriminado de antimicrobianos, de doses elevadas de corticoesteróides, de drogas arritmogênicas, nefrotóxicas ou hepatotóxicas determinam uma variável dessa patologia com sintomas diversos. Contudo, tentou-se traçar um perfil evolutivo de pacientes com COVID-19, conforme descrito na Tabela 2, onde os principais sintomas encontrados são a presença de febre (90\%), tosse seca (60-86\%), dispneia (53-80\%), fadiga (38\%), distúrbio gastrointestinal como náuseas, vômito ou diarreia (15-39\%) e mialgia (15-44\%). Além de sintomas neurológicos diversos, também podem ser encontrados anosmia e ageusia, presentes em até $64-80 \%$ dos casos, sendo sintoma isolado em até $3 \%$ desses pacientes. ${ }^{4}$

TABELA 2. Perfil evolutivo de pacientes com COVID-19.

\begin{tabular}{ll}
\hline Curso de Doença & Tempo Estimado \\
\hline Período de Incubação & -5 dias em média (variando entre 2 a 7 dias) \\
\hline Início dos Sintomas Respiratórios & -5 dias (podem ser tardio, como até 14 a 21 dias) \\
\hline Deterioração Clínica com Internação Hospitalar & - Mediana de 7 dias (intervalos interquartis de 3 a 9 dias) \\
\hline \hline Piora Radiológica & - Geralmente após o oitavo dia \\
\hline Tempo Médio de Sintomas & - 11,5 dias (casos graves e críticos: tempo mais prolongado) \\
\hline Melhora Clínica & - Geralmente em torno de 2 a 3 semanas \\
\hline Tempo Entre Início de Sintomas e o Óbito & - Variável, mas em geral de 2 a até 8 semanas \\
\hline \hline Tempo de Transmissão & - Variável e indeterminado (possivelmente de 10 a 21 dias) \\
\hline
\end{tabular}

A maioria dos casos de COVID-19, independente da idade, são leves ou mesmo assintomáticos, o que pode corresponder a até $85 \%$ dos pacientes. Entretanto, aproximadamente $15 \%$ progridem para formas graves e 5\% com necessidade de internação em Unidade de Terapia Intensiva (UTI) por necessitarem de suporte ventilatório e/ou hemodinâmico, conforme descreve e detalha a Tabela 3. Assim, a mortalidade geral por COVID-19 segue baixa, em torno de $2,8 \%$. No entanto, a letalidade dos casos graves é muito variável conforme diferentes estudos, chegando a $60 \%$ de mortalidade nos Estados Unidos entre os pacientes sob ventilação mecânica invasiva. ${ }^{14}$ 
TABELA 3. Classificação dos casos de COVID-19 conforme a gravidade.

\begin{tabular}{ll}
\hline \hline Classificação Sindrômica & Características \\
\hline \hline Casos Leves (81\%) & -Pneumonia Leve ou Ausente \\
\hline \hline & - Presença de ao menos um dos critérios: \\
& - Dispnéia; \\
& - Frequência Respiratória > 30 irpm; \\
Casos Graves (14\%) & - SaO2 $<93 \% ;$ \\
& - Relação PaO2/ FiO2 > 300; \\
& - Infiltrado Pulmonar > 50\%. \\
\hline & - Insuficiência Respiratória \\
Casos Crítico (5\%) & - Choque circulatório \\
& - Disfunção de Múltiplos Órgãos e Sistemas (DMOS) \\
\hline
\end{tabular}

A maioria dos pacientes com pulmonares (Tabela 4): $75 \%$ dos pacientes desfechos desfavoráveis tem relação apresentam pneumonia grave e $15 \%$ com complicações sistêmicas e SDRA.

TABELA 4. Potenciais complicações relacionadas a COVID-19.

\begin{tabular}{|c|c|}
\hline Complicações Sistêmicas & Fenótipos mais relevantes \\
\hline Respiratórias 5 & $\begin{array}{l}\text { - Pneumonia Grave } \\
\text { - Insuficiência Respiratória } \\
\text { - SDRA }\end{array}$ \\
\hline Cardiovasculares5 & $\begin{array}{l}\text { - Arritmias (supra e infra-hissianas) } \\
\text { - Infarto Agudo do Miocárdio Tipo I e Tipo II } \\
\text { - Miocardite } \\
\text { - Cardiomiopatia } \\
\text { - Síndrome de Takotsubo } \\
\text { - Choque Circulatório }\end{array}$ \\
\hline Hepáticas ${ }^{17}$ & $\begin{array}{l}\text { - Elevação de transaminases } \\
\text { - Elevação de bilirrubina } \\
\text { - Síndrome colestático }\end{array}$ \\
\hline Pancreáticas $^{12}$ & - Pancreatite (diferentes graus de acometimento) \\
\hline Tromboembólicas 5 & $\begin{array}{l}\text { - Tromboembolismo Pulmonar } \\
\text { - Trombose Venosa Periférica } \\
\text { - Doença Arterial Obstrutiva }\end{array}$ \\
\hline Neurológicas 5 & $\begin{array}{l}\text { - Encefalite e Meningite } \\
\text { - Síndrome de Guillain-Barre } \\
\text { - Crises Convulsivas } \\
\text { - Acidente Cerebrovascular Isquêmico } \\
\text { - Acidente Cerebrovascular Hemorrágico } \\
\text { - Polineuromiopatia } \\
\text { - Alterações de Consciência }\end{array}$ \\
\hline Inflamatórias 5 & $\begin{array}{l}\text { - Linfohistiocitose Hemofagocítica Secundária } \\
\text { - Tempestade de Citocinas }\end{array}$ \\
\hline Infecções Secundárias 5 & - Pneumonia Bacteriana e Fúngica \\
\hline
\end{tabular}


Emrelaçãoa eventos vasculares, sejam eles cerebrovasculares, cardiovasculares ou tromboembólicos, podem estar presentes em até 31 a 59\% dos casos. Complicações referentes as disfunções orgânicas, como neurológicas (mais de $8 \%$ dos casos), renais (mais de $9 \%$ dos casos) e hepáticas (19\% dos casos) estão envolvidas. Estas relacionamse a casos graves por desregulações do sistema imune e da resposta inflamatória, desencadeando complicações mais raras como a Síndrome de Tempestade de Citocinas e a Síndrome de Linfohistiocitose Hematofagocítica Secundária. ${ }^{4}$

Esses números foram muito variáveis ao redor da pandemia, tendo influência direta da qualidade assistencial, o que interferiu na diferença de desfechos entre serviços, ressaltando os momentos de maior ou menor saturação das instituições, conforme a incidência de novos casos. Inerente a isso, diante da sobrecarga dos serviços, com a falta de leitos e insumos adequados, há uma maior tendência que ocorra um aumento da mortalidade tanto dos pacientes com
COVID-19 como por outras causas nesse contexto. ${ }^{21}$ Isso foi evidenciado na Inglaterra, onde a sobrevida dos pacientes internados em Unidades de Terapia Intensiva aumentou de $58 \%$ para $80 \%$ do final de março para o final de julho de $2020 .^{22}$ Além disso, a veracidade desses dados sempre pode ser questionada, sobretudo, em locais onde os testes diagnósticos são escassos e a subnotificação é uma realidade constante. ${ }^{23,24}$

A presença de comorbidades apresenta uma grande relação com a gravidade, ${ }^{2,25}$ o que foi associado a um aumento de 12 vezes no risco de óbito, em uma avaliação de 300.000 pacientes com COVID-19 nos Estados Unidos. ${ }^{26}$ 60-90\% dos casos graves têm ao menos uma comorbidade, entre as quais as mais frequentes são a hipertensão arterial sistêmica (HAS) (45-57\%), doenças cardiovasculares (21-28\%), diabetes mellitus (DM) (17-34\%), doença renal crônica (13\%), doença pulmonar obstrutiva crônica (4-10\%), neoplasia maligna (6-8\%) e doença hepática crônica $(<5 \%), 4,25$ como bem descrita na Tabela 5.

TABELA 5. Comorbidades associadas a riscos de evolução para casos graves e para óbito.

\begin{tabular}{lcc}
\hline \multirow{2}{*}{ Comorbidade } & \multicolumn{2}{c}{ OR (IC95\%) } \\
\cline { 2 - 3 } Doença Renal Crônica & $2,56(0,63-10,45)$ & $3,20(2,52-4,06)$ \\
Hepatopatia Crônica & $1,45(0,703,01)$ & $1,80(1,35-2,39)$ \\
Doença Respiratória Crônica & $2,48(1,44-4,27)$ & $2,00(1,39-2,88)$ \\
Doença Cerebrovascular & $2,02(0,71-5,70)$ & $4,15(1,80-9,59)$ \\
Doença Cardiovascular & $1,70(1,05-2,78)$ & $2,98(2,51-3,53)$ \\
Diabetes Mellitus & $2,10(1,33-3,34)$ & $2,12(1,79-2,88)$ \\
Hipertensão Arterial Sistêmica & $2,33(1,42-3,81)$ & $2,61(2,19-3,17)$ \\
Neoplasia Maligna & $1,18(0,70-1,99)$ & $2,36(1,77-3,15)$ \\
\hline & & Fonte: Stokes et al. ${ }^{25}$
\end{tabular}

\section{Particularidades do Idoso com COVID-19}

\begin{tabular}{l}
\multicolumn{1}{c}{ Pacientes idosos possuem } \\
particularidades que podem levá-los a \\
apresentações clínicas distintas, com
\end{tabular}

uma frequência maior do que os demais indivíduos. $^{27}$ Nesse contexto, sinais e sintomas atípicos como quedas, piora do estado geral e alterações cognitivas ou comportamentais, como a presença de 
delirium, sobretudo naqueles com mais de 80 anos, podem ser observadas. ${ }^{28}$ Além disso, esses casos tendem a cursar com maior gravidade e mortalidade, o que é evidenciado por alguns trabalhos. ${ }^{13,29}$

Entre 74 e $86 \%$ dos pacientes internados apresentam idade superior a 50 anos4, que confere um aumento da mortalidade de $0,4 \%$ em pacientes com 55 anos; 1,4\%, para aqueles com 65 anos; 4,6\%, nos de 75 anos e $15 \%$ nos indivíduos com 85 anos30, conferindo um aumento de 20 vezes do risco de morte para os pacientes com idade superior a 80 anos, em comparação aos com idade entre 50 e 59 anos, ${ }^{31}$ podendo ser observado na Figura 5.

a)

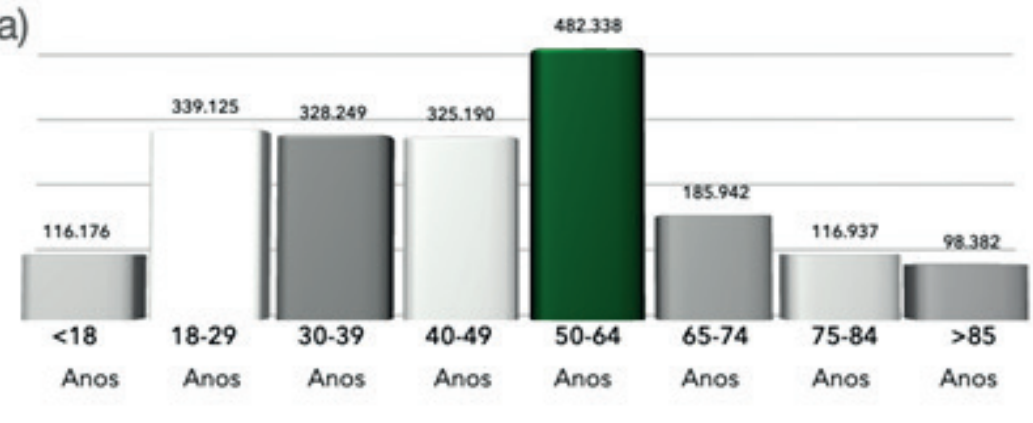

b)

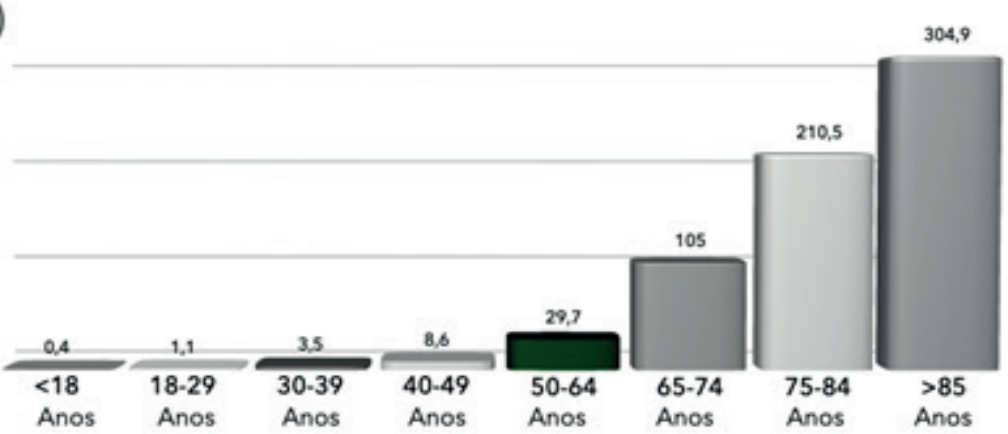

FIGURA 5. Casos de COVID-19 confirmados conforme a idade dos pacientes (a); Óbitos por COVID-19 em relação à progressão etária populacional (b). Fonte: Wiersinga et al. ${ }^{4}$

Esses achados são determinados por inúmeros fatores, entre os quais, destacamse a maior incidência de comorbidades, a polifarmácia e a fragilidade, ${ }^{27}$ sendo agravado ainda mais, pela maior dificuldade de acesso a serviços de saúde e, com isso, contribuindo com uma maior probabilidade de desfechos desfavoráveis. ${ }^{4}$

Apesar das comorbidades, como HAS, DM e doenças cardiovasculares, não apresentarem um maior risco de óbito nesses pacientes, em relação aos demais, elas são mais frequentes. Além disso, esses indivíduos tendem a ter um maior número de comorbidades associadas, o que também conferea elesum risco mais elevado, ${ }^{4,13}$ tendo sido evidenciado em uma série de pacientes idosos nos Estados Unidos, com idade média de 83 anos, onde 94\% apresentavam doenças crônicas. Destes, $55 \%$ necessitaram ser internados e $35 \%$ evoluíram para óbito. ${ }^{32}$ Outro aspecto que impacta nesses desfechos é a maior probabilidade de ocorrer uma tempestade de citocinas induzidas pelo vírus, SDRA e DMOS, o que também tem relação importante com gravidade e mortalidade. ${ }^{27}$ 


\section{Diagnóstico do COVID-19}

O rastreamento clínico deve sempre ser o norte de toda investigação diagnóstica. Portanto, uma avaliação clínica detalhada, que pode ser associada a exames laboratoriais e de imagem como a Ultrassonografia pulmonar e a Tomografia de tórax devem ser sempre levadas em consideração, se disponíveis. Tanto a apresentação clínica, como a laboratorial e as alterações de imagem são deveras variáveis. Quanto as alterações de imagem, destacamse as alterações intersticiais (infiltradas) que têm maior propensão de acometimento periférico, bilateral em lobos inferiores (vidro fosco na Tomografia de tórax) e linhas B na Ultrassonografia de tórax, podendo, em estágios mais tardios e graves, apresentar áreas de consolidação.33,34

Apesar de não termos um perfil único de evolução laboratorial, alguns achados são muito frequentes e auxiliam no diagnóstico, como a linfopenia, que é encontrada em até $83 \%$ dos casos, a elevação de marcadores inflamatórios (como proteína $\mathrm{C}$ reativa, fator de necrose tumoral alfa, e interleucina- 6 por exemplo) e de alterações da coagulação, como a elevação de D-Dímero ( $46 \%$ dos casos), de trombocitopenia e de prolongamento do tempo de protrombina. 4

A reação em cadeia da polimerase (rT-PCR) a partir de um swab nasofaríngeo é o teste padrão-ouro para o diagnóstico de COVID-19. A sua sensibilidade é muito variável, passando $33 \%$ no quarto dia de exposição para $62 \%$ no dia de início dos sintomas e $80 \%$ no terceiro dia de sintomas. A acurácia pode ser maior perante uma técnica rigorosa de coleta e quando a amostra for oriunda de um lavado bronco-alveolar. A identificação do antígeno viral também pode auxiliar no diagnóstico nos primeiros sete dias de sintomas. Testes sorológicos passam a ser úteis para o diagnóstico após o sétimo dia, quando a sensibilidade do rT-PCR tende a cair significativamente. O IgM pode permanecer por até 2 a 3 semanas, enquanto o IgG que tende a ser encontrado a partir de 14 dias do início dos sintomas pode permanecer por tempo ainda não determinado e com titulações variáveis. ${ }^{4}$

Os testes diagnósticos devem ser sempre pareados com a avaliação total do paciente, com os dados clínicos, laboratoriais e de imagem, com o intuito de reduzir resultados falsos negativos e potenciais erros diagnósticos. Portanto, casos com elevada probabilidade pré-teste, com resultados negativos, devem ter os exames repetidos, para evitar tais viéses. 4,35

\section{Tratamento dos pacientes com COVID-19}

O tratamento de pacientes com COVID-19 passou por inúmeras falácias até o momento, com muitas tentativas frustradas de implementações de diversas medicações e protocolos. Hoje, o que há de concreto é que o paciente necessita de um suporte individualizado, com vistas a um bom suporte ventilatório (Figura 6) e ao controle de sintomas. Além disso, apenas demonstramse de modo consensual entre as evidências, o uso racional de anticoagulantes, ao menos em doses profiláticas nos casos graves, podendo ser utilizadas doses mais elevadas na vigência de trombose, ou coma utilização de algoritmos que indiquem uma maior probabilidade de eventos tromboembólicos, e o uso de corticoesteróides em doses anti-inflamatórias em pacientes que necessitam de oxigênio. Nenhum outro tratamento até o momento teve seu uso corroborado por ensaios clínicos randomizados e com resultados significativos, com validação externa. 4,36 


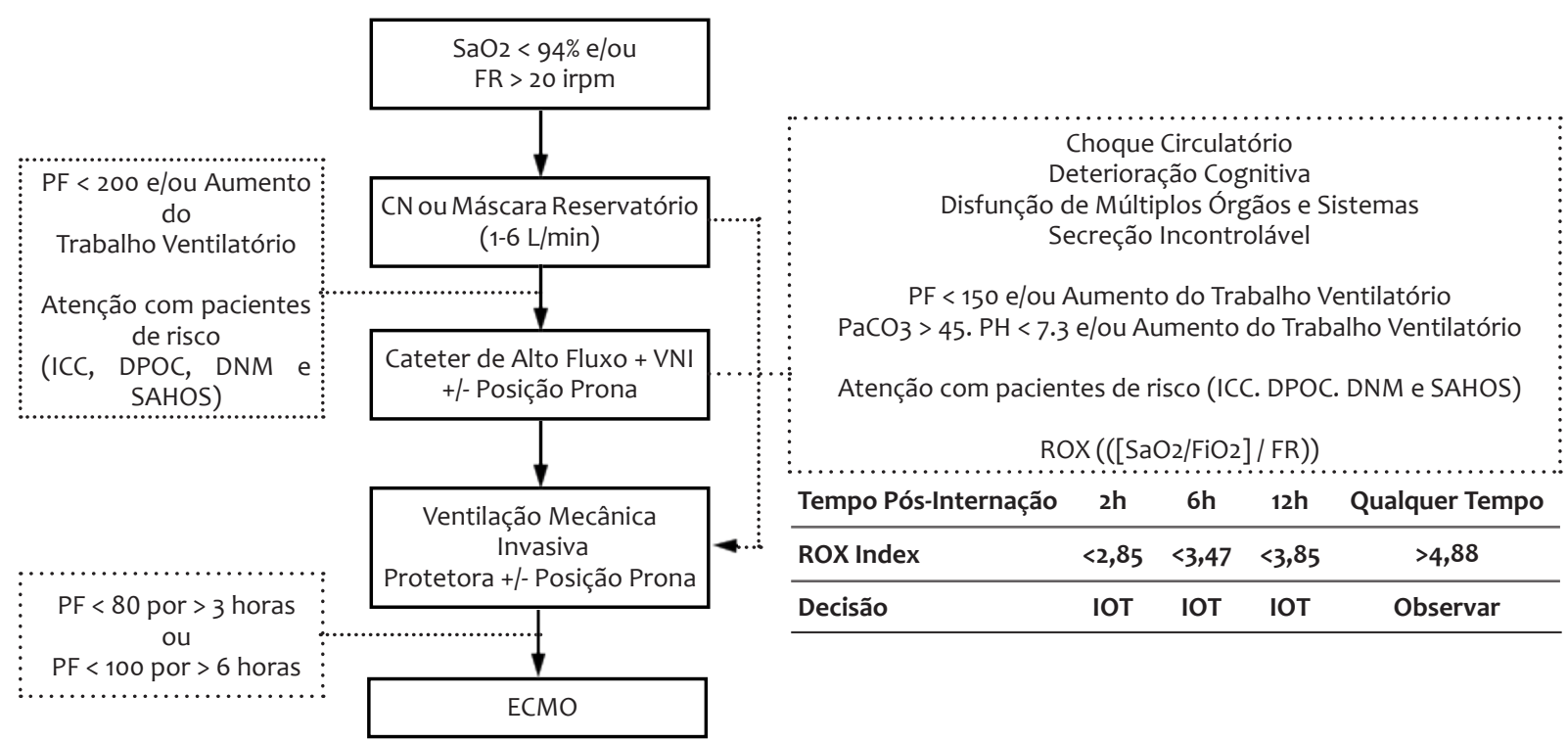

FIGURA 6. Fluxograma do suporte ventilatório do paciente com COVID-19 (FR: Frequência Respiratória; VNI: Ventilação não-invasiva; ECMO: Circulação extra-corpórea com membrana de oxigênio; ICC: Insuficiência Cardíaca Congestiva; DPOC: Doença pulmonar obstrutiva crônica; DNM: Doença neuromuscular; SAHOS: Síndrome de apnéia obstrutiva do sono; Protocolo Assistencial - UTI Adulto do Hospital Nossa Senhora das Neves).

\section{Transmissão da COVID-19: Como ocorre e como podemos evitar sua disseminação?}

A exposição direta interpessoal, com exteriorização de gotículas expelidas durante a fala, a tosse ou o espirro é a principal forma de contaminação. Sendo o risco de contágio diretamente proporcional a proximidade entre os indivíduos e o tempo de exposição (quanto maior o tempo e a proximidade, maior será o risco de contaminação). ${ }^{23}$ Portanto, a manutenção de um distanciamento social seguro de ao menos 1,5 a 2 metros, evitando reuniões e eventos sociais em ambientes fechados, assim como abraços e apertos de mão são medidas preventivas efetivas para essa disseminação. 2,4,32,37 Viagens de ônibus ou avião, portanto, devem ser desencorajadas como rotina, principalmente, em pacientes idosos durante o período de pandemia. Somado a isso, o uso de máscaras é de suma importância para evitar esse meio de contaminação. ${ }^{2,4,23,38}$
A transmissão, por meio indireto, por meio do contato com superfícies contaminadas, ainda carece de maior validação, sobretudo em situações. Contudo, pela possível permanência do vírus por períodos prolongados em diferentes estruturas, essa forma de contágio traz maiores preocupações, sobretudo perante o contato íntimo com indivíduos contaminados, ou mesmo dentro de instituições de saúde, onde o inóculo viral tende a ser maior. Por isso, para tentar evitar tal propagação, perante tais possibilidades, é de suma importância a higiene adequada das mãos com água e sabão ou com etanol $70 \%$ (efetivo na inativação viral), assim como a higienização de superfícies potencialmente contaminadas. $^{2,4,23,38,40}$

A transmissão por aerossóis (pequenas gotículas suspensas no ar) também foi relatada. Apesar de ter um menor impacto do que a por gotículas, essa via tem um risco adicional pelo tempo que os 
aerossóis podem permanecer em um ambiente fechado e pelo seu potencial de disseminação por distâncias maiores do que aquela relacionada à transmissão por gotículas, o que eleva ainda mais a indicação do uso de máscaras durante a pandemia em ambientes sociais, além da inidicação de manutenção dos ambientes com a maior ventilação possível. ${ }^{2,4,7,23,37,38}$ Outras potenciais rotas de transmissão, como por meio das fezes de indivíduos infectados e a transmissão vertical, não demonstraram um maior impacto na propagação da pandemia. ${ }^{2,4}$

A testagem populacional é uma forma efetiva de contenção de casos, pois os indivíduos infectados têm uma probabilidade maior de transmitir o vírus no estágio inicial da doença, quando os níveis de RNA em amostras respiratórias são mais elevados, levando a uma probabilidade significativa de

\section{CONSIDERAÇÕES FINAIS}

A pandemia por COVID-19 se apresentou como um cenário previamente visualizado apenas na ficção, com impacto social e econômico imensurável. Os pacientes idosos, por sua fragilidade, associados as comorbidades previamente instituídas, além de inúmeros outros fatores, tiveram desfechos ainda mais impactantes, com um maior número de casos graves, com mais internações hospitalares, incluindo Unidades transmissão por elementos pré-sintomáticos e mesmo por aqueles que não apresentam sintomas, os quais podem ser isolados previamente a isso, perante uma testagem prévia com diagnóstico preventivo. ${ }^{2,4,23}$

Por fim, a provável melhor estratégia para prevenção de novos casos e de contenção da pandemia é a vacinação. De forma consensual, não há até o momento medida mais viável para esse fim, nem mesmo para a qual haja tanta esperança em sua efetividade. Portanto, todas as pessoas devem ser vacinadas, seguindo o Programa Nacional de Vacinação. Os pacientes idosos são a grande prioridade nesse contexto, pois são os mais frágeis perante o cenário atual e os que representaram a maioria dos pacientes internados em hospitais, incluindo Unidades de Terapia Intensiva, durante os picos pandêmicos. ${ }^{2,4,23}$

de Terapia Intensiva, com subsequente maior mortalidade. Infelizmente, não há uma terapêutica consensual com grande impacto para mudança desses desfechos. Contudo, o uso racional de corticóides e anticoagulantes já são consensuais, além de um suporte ventilatório adequado e individualizado. $E$, por fim, a profilaxia demonstrou ter uma efetividade muito significativa, sobretudo perante a vacinação em massa da população.

\section{REFERÊNCIAS BIBLIOGRÁFICAS}

1. Organização Mundial de Saúde (OMS). Casos Confirmados no Brasil. https://covid19.who.int/ region/amro/country/br (Acessado em 05 de
Setembro de 2021).

2. Organização Mundial de Saúde (OMS). 
Transmission of SARS-CoV-2: Implications for infection prevention precautions. https:// www.who.int/publications/i/item/modesof-transmission-of-virus-causing-covid-19implications-for-ipc-precaution-recommendations (Acessado em 22 de Maio de 2021).

3. Mesas AE, Cavero-Redondo I, Bueno CA, Cabrera MAS, Andrfade SM, Sequí-Dominguez I, et al. Predictors of in-hospital COVID-19 mortality: A comprehensive systematic review and metaanalysis exploring differences by age, sex and health conditions. PLOS ONE. 2020. 15(11): e0241742.

4. Wiersinga WJ, Rhodes A, Cheng AC, Peacock SJ, Prescott H. Pathophysiology, Transmission, Diagnosis, and Treatment of Coronavirus Disease 2019 (COVID-19): A Review. JAMA. 2020 Aug $25 ; 324(8): 782-93$.

5. Gulyaeva AA, Gorbalenya AE. A nidovirus perspective on SARS-CoV-2. Biochem Biophys Res Commun. 2021 Jan;538:24-34.

6. Ashour HM, Elkhatib WF, Rahman MM, Elshabrawy HA. Insights into the Recent 2019 Novel Coronavirus (SARS-CoV-2) in Light of Past Human Coronavirus Outbreaks. Pathogens. 2020 Mar 4;9(3):186.

7. Zhu N, Zhang D, Wang W, Li X, Yang B, Song $J$, et al. A Novel Coronavirus from Patients with Pneumonia in China, 2019. N Engl J Med. 2020 Feb 20;382(8):727-33.

8. Lu R, Zhao X, Li J, Niu P, Yang B, Wu H, et al. Genomic characterisation and epidemiology of 2019 novel coronavirus: implications for virus origins and receptor binding. Lancet. 2020 Feb 22;395(10224):565-74.

9. Huang Y, Yang C, Xu X, Xu W, Liu S. Structural and functional properties of SARS-CoV-2 spike protein: potential antivirus drug development for COVID-19. Acta Pharmacol Sin. 2020 Sep 3;41(9):1141-49.

10. Gheblawi M, Wang K, Viveiros A, Nguyen Q, Zhong JC, Turner AJ, et al. Angiotensin-Converting Enzyme 2: SARS-CoV-2 Receptor and Regulator of the Renin-Angiotensin System. Circ Res. 2020 May 8;126(10):1456-74.

11. Liu $F$, Long $X$, Zhang $B$, Zhang $W$, Chen $X$, Zhang Z. ACE2 Expression in Pancreas May Cause Pancreatic Damage After SARS-CoV-2 Infection. Clin Gastroenterol Hepatol. 2020 Aug;18(9):212830.e2.

12. Vardhana SA, Wolchok JD. The many faces of the anti-COVID immune response. J Exp Med. 2020 Jun 1;217(6).

13. Wu Z, McGoogan JM. Characteristics of and Important Lessons From the Coronavirus Disease 2019 (COVID-19) Outbreak in China. JAMA. 2020 Apr 7;323(13):1239-42.

14. Cates J, Lucero-Obusan C, Dahl RM, Schirmer P, Garg S, Oda G, et al. Risk for In-Hospital Complications Associated with COVID-19 and Influenza - Veterans Health Administration, United States, October 1, 2018-May 31, 2020. MMWR Morb Mortal Wkly Rep. 2020 Oct 23;69(42):1528-34.

15. Chen T, Wu D, Chen H, Yan W, Yang D, Chen G, et al. Clinical characteristics of 113 deceased patients with coronavirus disease 2019: retrospective study. BMJ. 2020 Mar 26;368,m1091.

16. Xie $Y$, Wang $X$, Yang $P$, Zhang S. COVID-19 Complicated by Acute Pulmonary Embolism. Radiol Cardiothorac Imaging. 2020 April 1;2(2):e200067.

17. Liotta EM, Batra A, Clark JR, Shlobin NA, Hoffman SC, Orban ZS, et al. Frequent neurologic manifestations and encephalopathy-associated morbidity in Covid-19 patients. Ann Clin Transl Neurol. 2020 Nov 5;7(11):2221-30.

18. Leisman DE, Ronner L, Pinotti R, Taylor MD, Sinha P, Calfee CS, et al. Cytokine elevation in severe and critical COVID-19: a rapid systematic review, meta-analysis, and comparison with other inflammatory syndromes. Lancet Respir Med. 2020 Dec;8(12):1233-44.

19. Rawson TM, Moore LSP, Zhu N, Ranganathan $\mathrm{N}$, Skolimowska K, Gilchrist M, et al. Bacterial and Fungal Coinfection in Individuals With Coronavirus: A Rapid Review To Support COVID-19 
Antimicrobial Prescribing. Clin Infect Dis. 2020 Dec 3;71(9):2459-68.

20. Mudatsir M, Fajar JK, Wulandari L, Soegiarto $\mathrm{G}$, Ilmawan M, Purnamasari $Y$, et al. Predictors of COVID-19 severity: a systematic review and metaanalysis. F100oRes. 2020 Sep 9;9:1107.

21. Dennis JM, McGovern AP, Vollmer SJ, Mateen BA. Improving Survival of Critical Care Patients With Coronavirus Disease 2019 in England: A National Cohort Study, March to June 2020. Crit Care Med. 2021 Feb 26;49(2):209-14.

22. Woolf SH, Chapman DA, Sabo RT, Weinberger DM, Hill L, Taylor DDH. Excess Deaths From COVID-19 and Other Causes, March-July 2020. JAMA. 2020 Oct 20;324(15):1562-64.

23. Weinberger DM, Chen J, Cohen T, Crawford FW, Mostashari F, Olson D,et al. Estimation of Excess Deaths Associated With the COVID-19 Pandemic in the United States, March to May 2020. JAMA Intern Med. 2020 Oct 1;180(10):1336-44.

24. Richardson S, Hirsch JS, Narasimhan $M$, Crawford JM, McGinn T, Davidson KW, et al. Presenting Characteristics, Comorbidities, and Outcomes Among 5700 Patients Hospitalized With COVID-19 in the New York City Area. JAMA. 2020 May 26;323(20):2052-59.

25. Stokes EK, Zambrano LD, Anderson KN, Marder EP, Raz KM, El Burai Felix S, et al. Coronavirus Disease 2019 Case Surveillance - United States, January 22-May 30, 2020. MMWR Morb Mortal Wkly Rep. 2020 Jun 19;69(24):759-65.

26. Perrotta F, Corbi G, Mazzeo G, Boccia M, Aronne L, D'Agnano V, et al. COVID-19 and the elderly: insights into pathogenesis and clinical decision-making. Aging Clin Exp Res. 2020 Aug 16;32(8):1599-608.

27. Annweiler C, Sacco G, Salles N, Aquino JP, Gautier J, Berrut G, et al. National French Survey of Coronavirus Disease (COVID-19) Symptoms in People Aged 70 and Over. Clin Infect Dis. 2021 Feb 1;72(3):490-94.

28. Zhou F, Yu T, Du R, Fan G, Liu Y, Liu Z, et al.
Clinical course and risk factors for mortality of adult inpatients with COVID-19 in Wuhan, China: a retrospective cohort study. Lancet. $2020 \mathrm{Mar}$ 28;395(10229):1054-62.

29. Levin AT, Hanage WP, Owusu-Boaitey N, Cochran KB, Walsh SP, Meyerowitz-Katz G. Assessing the age specificity of infection fatality rates for COVID-19: systematic review, metaanalysis, and public policy implications. Eur J Epidemiol. 2020 Dec 8;35(12):1123-38.

30. Williamson EJ, Walker AJ, Bhaskaran K, Bacon $S$, Bates C, Morton CE, et al. Factors associated with COVID-19-related death using OpenSAFELY. Nature. 2020 Aug 20;584(7821):430-36.

31. McMichael TM, Currie DW, Clark S, Pogosjans S, Kay M, Schwartz NG, et al. Epidemiology of Covid-19 in a Long-Term Care Facility in King County, Washington. N Engl J Med. 2020 May 21;382(21):2005-11.

32. Simpson S, Kay FU, Abbara S, Bhalla S, Chung $J H$, Chung $M$, et al. Radiological Society of North America Expert Consensus Statement on Reporting Chest CT Findings Related to COVID-19. Endorsed by the Society of Thoracic Radiology, the American College of Radiology, and RSNA Secondary Publication. J Thorac Imaging. 2020 Jul;35(4):219-27.

33. Abrams ER, Rose G, Fields JM, Esener D. Pointof-Care Ultrasound in the Evaluation of COVID-19. J Emerg Med. 2020 Sep;59(3):403-08.

34. Goyal P, Choi JJ, Pinheiro LC, Schenck EJ, Chen R, Jabri A, et al. Clinical Characteristics of Covid-19 in New York City. N Engl J Med. 2020 Jun 11;382(24):2372-74.

35. Alhazzani W, Møller MH, Arabi YM, Loeb M, Gong MN, Fan E, et al. Surviving Sepsis Campaign: Guidelines on the Management of Critically III Adults with Coronavirus Disease 2019 (COVID-19). Crit Care Med. 2020 Jun 25;48(6):e440-69.

36. Islam N, Sharp SJ, Chowell G, Shabnam S, Kawachi I, Lacey B, et al. Physical distancing interventions and incidence of coronavirus disease 2019: natural experiment in 149 countries. BMJ. 
2020 Jul 15;370:m2743.

37. Hirose $R$, Ikegaya $H$, Naito $Y$, Watanabe $N$, Yoshida T, Bandou R, et al. Survival of Severe Acute Respiratory Syndrome Coronaviruss 2 (SARS-CoV-2) and Influenza Virus on the human skin: Importance of hand hygiene in Coronavirus Disease 2019 (COVID-19). Clin Infect Dis. 2020 Oct 3:ciaa1517.

38. Peto J, Alwan NA, Godfrey KM, Burgess RA, Hunter DJ, Riboli E, et al. Universal weekly testing as the UK COVID-19 lockdown exit strategy.
Lancet. 2020 May 2;395(10234):1420-21.

39. Kampf G, Todt D, Pfaender S, Steinmann E. Persistence of coronaviruses on inanimate surfaces and their inactivation with biocidal agents. J Hosp Infect. 2020 Mar;104(3):246-51.

40. Guo ZD, Wang ZY, Zhang SF, Li X, Li L, Li C, et al. Aerosol and Surface Distribution of Severe Acute Respiratory Syndrome Coronavirus 2 in Hospital Wards, Wuhan, China, 2020. Emerg Infect Dis. 2020 Jul;26(7):1583-91. 